\title{
Study on coupling degree of rail transit capacity and land use based on multivariate data from cloud platform
}

\author{
Quanhua Hou', Yaotian Xing ${ }^{1}$, Di Wang ${ }^{1}$, Jiachen Liu², Xiaoyang Fan ${ }^{1}$ and Yaqiong Duan ${ }^{1 *}$ (D)
}

\begin{abstract}
The study of exploring the internal connection between rail transit and land use is of great significance for the coordinated development of urban space and rail transit construction, and it is also important for the intensive use of land affected by rail transit stations. The land use structure and population density surrounding the stations of Line 1.2.3 of Xi'an Rail Transit were clustered by SPSS for identifying the rail transit stations with high population density. Subsequently, We have established an indicator system of urban land use and rail transit operation capabilities based on multivariate data, and explored the coordinated relationship between rail transit and land use through data envelopment analysis (DEA) evaluation methods at high population density stations. Besides, the coupling degree of land use in rail transit stations with high population density was evaluated, and the key indicators affecting the coupling degree were further analyzed in Xi'an. In conclusion, this study finds that the relationship between rail transit capacity and land use of high population density rail transit stations is unbalanced. Hence, to promote the sustainable development of rail transit capacity and surrounding land, it is suggested that we should confine the development of land use intensity around the station, improve the service functions of small-scale living areas, and optimize the travel environment intended for short-distance travel. For residents, they are encouraged to choose the mode of rail transit for their long-distance travel. At the same time, the peak passenger flow at the stations should be evacuated accordingly.
\end{abstract}

Keywords: High population density rail transit station, Rail transit capacity, Land use, Coupling degree, DEA, Multivariate data

\section{Introduction}

With the rapid development of Chinese urban rail transit system construction, the development mode of building a station-city integration has become the mainstream of the times. However, the coordination relationship between rail transit and the surrounding land development is not optimistic. On the one hand, many stations do not reach the designed passenger flow. On the other hand, the space development around the station does not take into account the connection with rail transit $[1,2]$. Therefore, it is important to understand the coordination relationships between the rail station and land use. European and American countries first proposed research on the coordination relationship between rails and cities in order to

\footnotetext{
* Correspondence: duanyaqiong@chd.edu.cn

'School of Architecture, Chang'an University, Xi'an, Shaanxi, China Full list of author information is available at the end of the article
}

solve the problems of the spread of large cities and the decline of population density in urban centers. In the 1990s, Peter Calthorpe proposed the TOD development model [3], and Robert Cervero made a lot of case studies in the urban development of public transportation $[4,5]$. Although rail transit and coordinated urban development can bring benefits to the urban economy, transportation, society and environment [6], the efficiency of rail transit development is low due to the inconsistency of the two systems during the actual development process [7, 8]. Therefore, many scholars have emphasized the research on the level of coordinated development [6,9], but these studies address the low density of urban sprawl in European and American countries [10].Nevertheless, urban population density in China is much higher than that in the most European and American cities, and the rail stations in China generally locates in urban core areas with higher 
population density [11, 12], bring unique development stage and problems. Hence, according to the characteristics of high resident and employed population density stations, it is requisite to coordinate the relationship between the rail stations with high population density and the land use around them in China [13].

The existing studies regarding to the urban rail transit and land use interaction, indicate that the impact of urban rail transit on land use in the station area mainly concentrated on the intensity of land development, accessibility of land parcels, land use structure as well as functional complexity [14-19].The coordination relationship between the rail transit station and the surrounding land use is generalized to the degree of coupling [20]. Within the scope of rail transit, the proportion of residential, public service and commercial land use has significantly changed, and the intensity of land development has improved due to the rail transit improves public accessibility, its location advantage is improved, attracting land use models with higher output efficiency [16]. Some studies have found that rail transit promotes the differentiation of surrounding commercial spaces and the formation of commercial hot spots, and uses the POI information entropy to indicate the diversity of activity spaces, after studying the internal and external mechanisms of rail transit and commercial spaces [14, 21]. In addition, in the study of low-carbon transportation modes, the scholars found that high road network density can effectively promote residents to choose low-carbon mode of travel, such as walking, cycling and public transit. While the motor vehicle and the travel by public transit form a competitive relationship [22-26].

The analysis methods are mainly based on lorry theory model, mathematical programming, input-output theory and urban economic theory which are belonged to the category of the typical analysis methods. Some widely used model methods include disaggregate residential allocation model (DRAM), projective optimization land use system (POLIS), micro-simulation model (MASTER) for transportation, housing, employment, etc. [27],they rely on a variety of additional constraints in the process of application. Some researches on the coordination degree model mainly include sequence parameter evaluation methods based on cooperative theory, system dynamics evaluation methods, data envelopment analysis (DEA), and fuzzy evaluation methods in China [28]. The differences between the evaluation methods are manifested in the selection of mathematical models, and the selection of the essential research indicators of such differences varies. Research models based on synergy theory usually use rough land use indicators and traffic volume as research objects, and cannot reflect the role of factors in a specified environment. Although the fuzzy evaluation method can make fuzzy objects close to the real situation through accurate quantification, when the index set is too large, the relative membership resolution between the indexes is low, which easily causes the problem of invalid evaluation results. The DEA evaluation model is based upon the relationship model between input-output model, which adapts to the analysis of various input-output factors. Since it does not need to give index weights in advance and avoids subjective assumptions [29]. It also evaluates the dynamic process that focuses on the system simultaneously. Notably, the results not only focus on the system evaluation, but also reflect the optimization direction of the system which is beneficial for decision makers to make adjustments in the follow-up work [25]. The DEA evaluation model is extensively applied to the study of the coordination relationship between public transportation and land use. Generally speaking, the input and output indicators are selected, which are comprised of population density, land development intensity, various construction land area, regional economic output, public transportation volume and sharing rate, and density of line net, etc. [30-33]. Studies figure out the impact of individual factors on the evaluation system by analyzing the causes of invalid decision making units(DMU), and bring forth momentous influencing factors that hinder the development of the evaluation system $[23,26]$. However, the multi-factor input and output analysis leads to complicated calculations and difficult to effectively implement, making the DEA evaluation model limited in the application of a large number of factor analysis.

The paper are organized as follow: we firstly classifies Xi'an rail transit stations in accordance with the characteristics of land use and population density. Then, based on the theoretical study concerning the interaction between rail transit and land use around the site, a DEA evaluation model is established by combining the indicator system. Finally, the DEA evaluation model is used to analyze the coordination degree between land development and rail transit operation of $\mathrm{Xi}$ 'an high-population density stations, so as to thoroughly explore the influence of various land use and rail transit transportation indicators on the coordination degree. The results can provide policy suggestions for transport and urban planning institutions in rail transit and urban space integration construction.

\section{Selection of research subject}

The Xi'an subway was put into operation in 2011. At this stage, lines 1-4 have been put into operation. Line 1 , Line 2 , and Line 3 are the backbone, connecting the main commercial and residential areas. Line 1, 2 and 3 mentioned in this research now have built 63 stations, including 3 transfer stations. Specific passenger flow varies from station to station. Surrounding land near to stations involves all districts across Xi'an city. Moreover, 
these districts are also greatly varied from one another in population, land property, land economic profits, and other aspects. In this research, cluster analysis was used to classify the population and land use structure characteristics around the site. Finally, a sample of 20 highdensity subway stations in Xi'an was derived and used to support the data envelope analysis of this research. The research will explore coupling characteristics of subway transportation capacity and land use around high population density rail transit station in Xi'an.

The study selected the area within 10-15 min of walking distance (ie $800 \mathrm{~m}$ from the rail transit station) as the service area of the station. Both the population of employment and residence are crucial factors that may exert certain influence on the passenger flow at the station. The spatial distribution characteristics of the high population density of living and employment are the embodiment of the land use [34-36]. That is to say, combined with station function and population density factors, station type clustering indicators are thus selected: the proportion of residential land in the affected area of the station, the proportion of commercial land, the proportion of public land, industrial land ratio, free land ratio, as well as the number of residents and employed population in the affected area (Table 1).

Use Arc GIS 10.2 to calculate the data of land use structure and the spatial distribution data of employment and residence by mobile phone signaling of China Unicom at each station, in Xi'an in November 2017 (Fig. 1). Based on SPSS 24.0, the seven types of subway stations obtained by clustering 63 subway stations in Xi'an. Two of these categories belong to special types of sites, including those based on educational land and industrial land. There are two types of sites that are still in the development stage, including types with non construction land and low population density, which are not the focus of research. The population density of three types of the stations is higher than the others, and the land use of the two types is dominated by commercial and public service facilities. The influencing factors of the coordination relationship of these stations are complex, such as the location, policy, and economic factors other than land use, so they are not considered in the study. 20-study samples were identified as high population density stations with balanced land type and high population density (Table 2 and Fig. 2).

\section{Research method and Indicator system DEA evaluation method}

The evaluation system of Data Envelopment Analysis (DEA) uses mathematical programming as a tool to construct the suspended hyperboloids on the whole by using the observed sample points to evaluate the relative effectiveness of multi-input and multi-output systems of the same type. This method combines decision-making units (DMUs) into groups to be evaluated, and conducts comprehensive analysis through input-output ratios. Then it takes the weight of each input and output indicator of the DMU as a variable, and uses linear programming technology to evaluate and calculate an effective production frontier. This model can determine whether each DMU is valid for DEA based on the distance between each DMU and the effective production boundary. The reasons why non-DEA is effective or weak DEA is effective are pointed out using the projection method, and the direction and degree of optimization are calculated $[32,36]$.

.In this paper, the basic model $C^{2} R$ model of DEA is selected for calculation. decision unit $D M U_{j}(j=1,2, \ldots$, $n)$; the input vector is $X_{j}=\left(x_{1 j}, x_{1 j}, \ldots, x_{m j}\right)^{T}, x_{j} \geq 0, j=1$, $2, \cdots, m$, the output vector is $Y_{j}=\left(y_{1 j}, y_{2 j}, \ldots, y_{m j}\right)^{T}, y_{j} \geq 0$, $j=1,2, \cdots, m$, the weight vector corresponding to the $\mathrm{m}$ kinds of inputs is $V=\left(v_{1}, v_{2}, \ldots, v_{m}\right)^{T}, v_{i} \geq 0, i=1,2, \cdots$, $m$, the weight vector corresponding to the $\mathrm{s}$ kinds of output is $U=\left(u_{1}, u_{2}, \ldots, u_{s}\right)^{T}, u_{i} \geq 0, i=1,2, \cdots, s$ 。

Write the input and output vector of $D M U_{j 0}$ as $\left(x_{j 0}\right.$, $\left.y_{j 0}\right)$, here can be abbreviated as $\left(x_{0}, y_{0}\right)$, the efficiency evaluation indicator of each decision unit $D M U_{j 0}$ is:

$$
h_{j 0}=\frac{u^{T} Y_{0}}{v^{T} X_{0}}
$$

When evaluating the effectiveness of $D M U_{j 0}$, taking $\mathrm{u}$ and $\mathrm{v}$ as variables, use $\left(u^{T} Y_{0}\right) /\left(v^{T} X_{0}\right) \leq 1$ as the constraint, Constructing the optimal indicator of efficiency

Table 1 Indicators for the classification of Xi'an rail transit stations

\begin{tabular}{llllll}
\hline Indicator & Mean & Max. & Min. & S.D. & source \\
\hline Proportion of residential land & 0.42804 & 0.680441 & 0 & 0.156684 & Land use database \\
Proportion of public land & 0.148134 & 0.682141 & 0 & 0.135056 & Land use database \\
Proportion of commercial land & 0.101403 & 0.343221 & 0 & 0.074458 & Land use database \\
Industrial land ratio & 0.08274 & 0.506808 & 0 & 0.10992 & Land use database \\
Free land ratio & 0.151797 & 0.878061 & 0 & 0.205019 & Land use database \\
Number of residents & $16,953.68$ & 30,801 & 4287 & 6278.334 & Cell phone signaling data \\
Employed population & $15,300.37$ & 26,368 & 4132 & 5528.723 & Cell phone signaling data \\
\hline
\end{tabular}




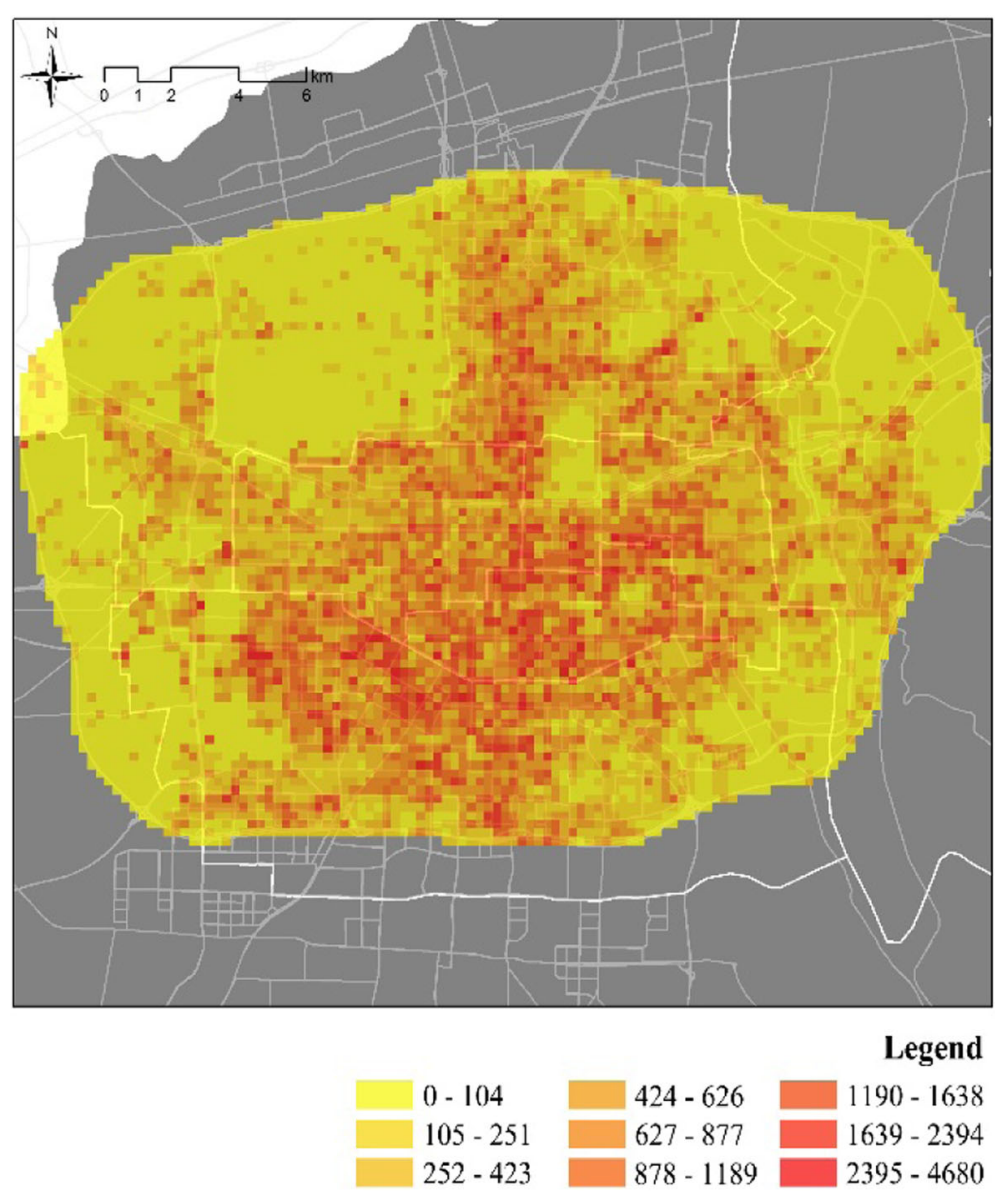

Fig. 1 Population density distribution by mobile phone signaling

indicator of decision-making unit with DMUj0 efficiency indicator $\left(\max h_{j 0}\right)$ being the largest, as follows:

$$
\begin{aligned}
& \max _{j 0}=\frac{u^{T} Y_{0}}{v^{T} X_{0}} \\
& \text { s.t } \frac{u^{T} Y_{0}}{v^{T} X_{0}} \leq 1
\end{aligned}
$$

Carrying out Charnes-Cooper transformation on efficiency indicator model to obtain equivalent linear programming model $\min \theta$

s.t. $\sum_{j=1}^{n} x_{j} \lambda_{j}+s^{-}=\theta x_{0}$

$\sum_{j=1}^{n} y_{j} \lambda_{j}-s^{+}=y_{0}$

$$
\lambda_{j} \geq 0(j=1,2, \cdots, n), \theta \in R, s^{-} \geq 0, s^{+} \geq 0
$$

If $D_{\mathrm{C}^{2} \mathrm{R}}^{\mathrm{I}}$ If the optimal solution satisfies $\theta_{0}<1$, then $D M U_{j 0}$ is said to be non-DEA valid.

If $D_{\mathrm{C}^{2} \mathrm{R}}^{\mathrm{I}}$ The optimal solution satisfies $\theta_{0}=1$, and $\sum_{j=1}^{n}$ $x_{j} \lambda_{j}^{0}=\theta^{0} x_{0}, \quad \sum_{j=1}^{n} y_{j} \lambda_{j}^{0}=y_{0}\left(\right.$ ie $\left.s^{0-}=0, s^{0+}=0\right)$, then $D M U_{j 0}$ is said to be weak DEA effective.

Table 2 High population density rail transit stations in Xi'an

\begin{tabular}{ll}
\hline Rail transit line & Station name \\
\hline Line 1 & Yu Xiang Men, Sa Jin Qiao, Chao Yang Men, Ban Po \\
Line 2 & Feng Cheng 5-Lu, Shi Tu Shu Guan, Da Ming Gong Xi, Long Shou Yuan, An Yuan Men, Yong Ning Men, Nan Shao Men, San Yao \\
Line 3 & Zhang Ba Bei Lu, Yan Ping Men, Tai Bai Nan Lu, Bei Chi Tou, Yan Xing Men, Xian Ning Lu, Chang Le Gong Yuan, Hu Jia Miao \\
\hline
\end{tabular}




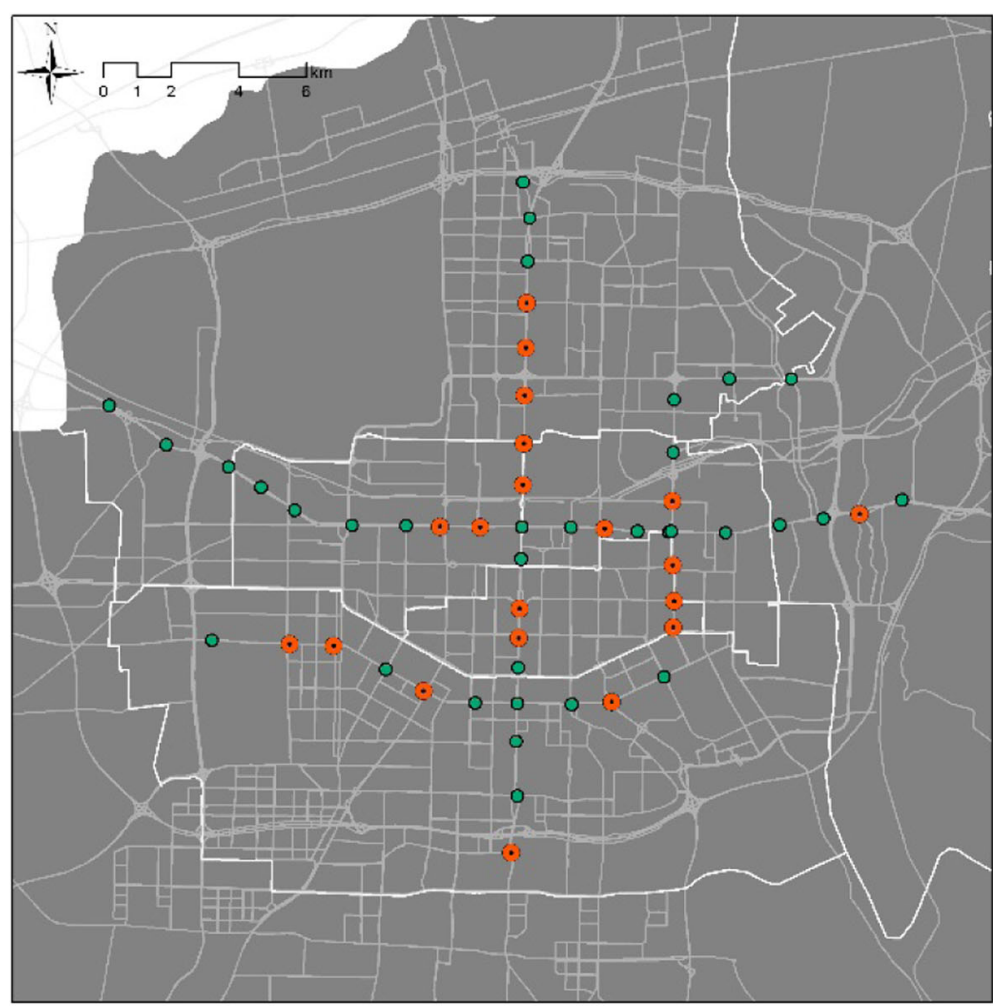

Legend

- High population density station

- Other station

Fig. 2 Spatial distribution of high population density rail transit stations with high population density

The input type $C^{2} R$ model was used to evaluate the coordination degree of the intensive land use system (L) and the station operational efficiency system (T) around the rail transit station. The intensive land use system (L) and the station operational efficiency system (T) around the rail transit station are regarded as an input-output system. The intensive level of the land around station is used as the system input, and system output is the operational efficiency of the station. The system input and output effectiveness is the degree of coordination of the station intensive use (L) to the operational efficiency ( $\mathrm{T}$ ) around the station, which is recorded as $\theta_{i}\left(\theta_{i} \leq 1\right)$.On the contrary, the station operation efficiency is taken as the system input, and the land surrounding the station in $800 \mathrm{~m}$ is used as the system output, that is, the degree of coordination of $(\mathrm{T})$ pair $(\mathrm{L})$ is recorded as $\theta_{i}{ }^{\prime}\left(\theta_{i}{ }^{\prime} \leq\right.$ $1)$, the larger the value of $\theta$, the higher the matching degree of the input system to the output system.

Establishing a coupling model of system interaction, although the degree of coordination between systems can reflect the degree of coordination between rail transit capacity and land use around the station, the actual situation of land use and rail transit capacity is lacking. Considering, it may lead to the situation that the two subsystems have low coordination degree but high coupling degree. Therefore, the comprehensive coordination indicator is added.

$$
\begin{aligned}
& C=m\left(\frac{\prod_{i=1}^{m} U_{i}}{\sum_{i=1}^{m} U_{i}}\right)^{\frac{1}{m}}, i=1,2 \ldots, m \\
& \theta_{L T}=\sqrt{C \times T} \\
& T=\sum_{i=m} \alpha_{i} U_{i}
\end{aligned}
$$

$C$ is the degree of system coordination, $\mathrm{m}$ is the number of subsystems of the coupled system, $T$ is the comprehensive coordination indicator of the decision unit subsystem, and $U_{i}\left(U_{i} \leq 1\right)$ is the coordination degree of the subsystem. $\alpha_{i}$ is the weight of the subsystem to be determined. In order to meet the coordinated development of Xi'an rail transit station and surrounding land use, it is equally important in the coupled system. The system weight of the land use system and the rail transit system is $0.5 . \theta_{L T}$ is the coupling degree between land intensive use and station capacity of the rail transit station $i$. 
In the DEA evaluation system, the impact of the input or output indicator on the evaluation system is analyzed by removing one of the evaluation indicators. The original evaluation indicator system is represented by $D$, and $D^{i}$ represents the evaluation indicator system after the $\mathrm{i}$-th indicator is removed from $D$.

$$
\theta_{j}(D)-\theta_{j}\left(D^{i}\right) \geq 0, j=1,2, \ldots, n
$$

$\theta_{j}(D)$ represents the coordinated development indicator of the $j$-th $D M U$ in the evaluation system $D ; \theta_{j}\left(D^{i}\right)$ represents the coordinated development of the $j$-th $D M U$ in the evaluation system Di.

$S_{j}(i)$ is the change in coordination degree after $i$ is removed from $D M U_{j}$ which can be expressed as follows:

$$
S_{j}(i)=\frac{\theta_{j}(D)-\theta_{j}\left(D^{i}\right)}{\theta_{j}\left(D^{i}\right)}, j=1,2, \ldots, n
$$

Then the larger $S_{j}(i)$ is, the greater the influence of the $i$ on the coordinated development of the evaluation system.

Assume that the $\mathrm{p}$ and $\mathrm{q}$ indicators respectively satisfy: $S_{j}(p)=\max S_{j}(i)$ with $S_{j}(q)=\min S_{j}(i)$ Then, the $\mathrm{p}$ and q indicators are respectively the maximum and minimum evaluation indicators of the evaluation unit invalid (Table 3).

\section{Evaluation indicator}

Based on the previous research, the development intensity, accessibility, facility service level and functional compounding degree have the greatest impact on the operational efficiency of rail transit [14-19]. The land development intensity was captured by three factors: floor area ratio, building density, and point of interest (POI) density. The accessibility level of the station are defined by three factors: bus line, parking lot density and bicycle density. In terms of service levels, a high land proportion of public and commercial facilities can carry more functions of service, leading to higher service levels accordingly. Finally, the volume of rail transit is affected by the frequency of trains and the maximum allowable traffic density of the line, which is mainly manifested in the passenger flow at the maximum section of the line during peak hours. Therefore, the capacity of the subway is measured by the total number of passengers per day, the average daily number of trips, and the total number of subway trips per day. The travel intensity of rail transit at each station is measured by the length of the travel interval per station. A land intensive use indicator system (L) and a rail transit indicator system $(\mathrm{T})$ are set up, which has been shown in Table 4.

\section{Collection of data}

The study focus on the $800 \mathrm{~m}$ range around the stations with high population density as the affected area in the built-up area of Xi'an. The 0.64 million points of interest data were captured from the application programming interface (API) of Gao de Map, and the number of shared bicycles in the catchment areas of the stations are obtained from the application programming interface (API) of Mobike interface. The information on the status of land use in Xi'an are extracted by Arc GIS 10.2, and the land development intensity and land use structure of the affected area are calculated by the same software The Xi'an rail transit and bus operation data were obtained from the Xi'an Rail Transit Group (Table 5).

\section{Data and result}

\section{Results of DEA evaluation}

The results of the coordinated development degree and coupling degree evaluation of the intensive use system and station operational efficiency system around the selected station are shown in Table 6. According to the analysis results, it can be seen that the efficiency of rail transit on land use is higher than the conversion efficiency of rail transit on land use. Increasing investment in land use is of great significance to the coordinated development of the system. The degree of mutual coordination is not notable in the systems, but due to the obvious differences in the overall coordination coefficients of the subsystems, the rail transit and land use systems show different levels of coupling at each station. Therefore, the development level of the station itself also makes a significant difference on the degree of coupling.

The coupling degree of the capacity of the rail transit and the surrounding land use $\left(\theta_{L T}\right)$ ranges from $[0,1]$. The larger the $\theta_{L T}$, the higher the coupling between the intensive use of land and rail transit operations around the station. Dong Wei has studied the classification and division criteria of coordination degree by using uniform distribution function [37]. The evaluation criteria of coupling degree are shown in Table 7 and Fig. 3.

On account of the development level of land use and rail transit capacity in high population density stations in Xi'an, these stations can be divided into four types according to the mutual effectiveness between the systems,

Table 3 Reasons for invalid DMU

\begin{tabular}{lll}
\hline Calculation results & If it is an input indicator & If it is an output indicator \\
\hline$S_{j}(q)$ & Too much investment or use efficiency is too low & The impact is low and the output is too small. \\
$S_{j}(p)$ & Too little investment to restrict development & The degree of influence is high and the output is too large. \\
\hline
\end{tabular}


Table 4 Definition of evaluating indicators

\begin{tabular}{|c|c|c|c|}
\hline Classification & Category & Indicator & Measurement \\
\hline \multirow[t]{11}{*}{ Land intensive use indicator } & Floor area ratio & L1 & Building area divided by land area \\
\hline & Building density & L2 & Building floor area divided by land area \\
\hline & Land use information entropy & L3 & $\begin{array}{l}H_{L}=-\sum_{i=1}^{n} A_{i} \ln A_{i} \\
A_{i}: \text { The area of the } i \text {-type land area in the } \\
\text { affected area as a percentage of the total } \\
\text { land area in the area; } \\
n: \text { the number of land use types in the } \\
\text { area }\end{array}$ \\
\hline & Proportion of land for public facilities & $\llcorner 4$ & $\begin{array}{l}\text { Area of land for public facilities divided by } \\
\text { land area }\end{array}$ \\
\hline & Proportion of land for commercial facilities & L5 & $\begin{array}{l}\text { Area of land for commercial facilities divided } \\
\text { by land area }\end{array}$ \\
\hline & Proportion of land for resident & L6 & $\begin{array}{l}\text { Area of land for resident divided by land } \\
\text { area }\end{array}$ \\
\hline & Density of facilities POI & L7 & Total POI divided by land area \\
\hline & Facility POI information entropy & L8 & $\begin{array}{l}H_{P}=-\sum_{i=1}^{n} P_{i} \ln P_{i} \\
P_{i}: \text { The percentage of POI in the } i \text {-type land } \\
\text { in the affected area as a percentage of the } \\
\text { total land area in the area; } \\
n: \text { the number of POI types in the area }\end{array}$ \\
\hline & Bus line density & L9 & $\begin{array}{l}\text { Total length of bus lines in the area divided } \\
\text { by land area }\end{array}$ \\
\hline & Parking lot density & L10 & Number of parking lots divided by land area \\
\hline & Bicycle density & L11 & Number of Mobike divided by land area \\
\hline \multirow[t]{4}{*}{ Rail transit capacity indicator } & Average daily number of passengers & $\mathrm{T} 1$ & $\begin{array}{l}\text { Obtained from the statistics of the rail transit } \\
\text { departments }\end{array}$ \\
\hline & Average daily number of rail transit interval & $\mathrm{T} 2$ & $\begin{array}{l}\text { Obtained from the statistics of the rail transit } \\
\text { departments }\end{array}$ \\
\hline & Average daily number of trains & T3 & $\begin{array}{l}\text { Obtained from the statistics of the rail transit } \\
\text { departments }\end{array}$ \\
\hline & Per capita rail transit interval & T4 & $\begin{array}{l}\text { Daily average number of rail transit interval } \\
\text { divided by daily average number of passengers }\end{array}$ \\
\hline
\end{tabular}

as is shown in Table 8. High, medium and low refers to the relative effectiveness level of rail transit and land use. Gradient is divided according to the overall effectiveness level of the system. To be specific, low level effectiveness is lower or equal to 0.68 , medium level effectiveness is greater than 0.68 but below 0.80 , and high-level effectiveness is between 0.80 and 1 . The overall characteristics of the technical efficiency of the coupling between two subsystems are as follows: Most of the rail transit stations in the running-in phase, except Long Shou Yuan station and Zhang Ba North Road station, has low technical efficiency which is at the level of intermediate coordination.

The coupling degree between the land intensive use system (L) and the station operation system (T) of the high population density rail transit station in Xi'an is insufficient, and the high-level coupling ratio is low, which means that it is urgent to improve the coupling degree between (L) and (T). The coupling degree of most stations is at a low level because the coordination degree of $(\mathrm{L})$ to $(\mathrm{T})$ is significantly lower than that of $(\mathrm{T})$ to $(\mathrm{L})$, indicating that the coordination degree between the two directions is not balanced, and that it is essential to invest in the intensive land use of the stations with more energy to stimulate its development.

The overall coupling degree of rail transit line 1 is at a low level, characterized by low-mid and mid-high coupling types. Land use at each station does not effectively support rail transit capacity. Although the overall coupling degree of rail transit line 2 is higher than that of line 1 and line 3, their coupling characteristics show that the land use to transport capacity support effect is lower than the reverse, and the coupling type is mid-high and high-high. Rail transit Line 3 was built later than Lines 1 and 2 , and the whole is in a phase-by-step phase, with various station coupling types being covered (Fig. 4). 
Table 5 Summary of data collection

\begin{tabular}{|c|c|c|c|c|c|}
\hline Indicator & Sample size & Mean & Max. & Min. & S.D. \\
\hline L1 Floor area ratio & 20 & 1.7045 & 2.18 & 1.24 & 0.261887 \\
\hline L2 Building density & 20 & 0.338 & 0.49 & 0.23 & 0.059127 \\
\hline L3 Land use information entropy & 20 & 2.092 & 2.76 & 1.21 & 0.397021 \\
\hline L4 Proportion of land for public facilities & 20 & 15.2435 & 32.98 & 5.2 & 6.819336 \\
\hline L5Proportion of land for commercial facilities & 20 & 12.5235 & 19.72 & 2.68 & 4.150053 \\
\hline L6 Proportion of land for resident & 20 & 54.883 & 68.04 & 44.56 & 7.227254 \\
\hline L7 Density of facilities POI & 20 & 14.1355 & 27.74 & 6.19 & 5.42126 \\
\hline L8 Facility POI information entropy & 20 & 1.399 & 1.56 & 1.27 & 0.068695 \\
\hline L9 Bus line density & 20 & 39.0165 & 66.24 & 16.12 & 11.59125 \\
\hline L10 Parking lot density & 20 & 73.3955 & 117.11 & 27 & 23.72685 \\
\hline L11 Bicycle density & 20 & 5.62 & 7.24 & 2.82 & 1.241306 \\
\hline T1 Average daily number of passengers & 20 & $42,643.6$ & 64,278 & 20,713 & $15,186.62$ \\
\hline T2 Average daily number of rail transit interval & 20 & $327,959.3$ & 595,718 & 124,959 & $146,516.8$ \\
\hline T3 Average daily number of trains & 20 & 513.54 & 603.4 & 450.3 & 73.46119 \\
\hline T4 Per capita rail transit interval & 20 & 7.509 & 10.09 & 5.9 & 1.232177 \\
\hline
\end{tabular}

Table 6 Coupling degree statistics of land intensive use and rail transit capacity

\begin{tabular}{|c|c|c|c|c|c|}
\hline$\overline{\mathrm{DMU}}$ & $\theta$ & $\theta^{\prime}$ & C & $T$ & $\theta_{L T}$ \\
\hline Yu Xiang Men & 0.591303 & 1 & 0.872426 & 0.795652 & 0.48184 \\
\hline Sa Jin Qiao & 0.548807 & 1 & 0.837472 & 0.774404 & 0.420605 \\
\hline Chao Yang Men & 0.558463 & 1 & 0.845907 & 0.779232 & 0.434489 \\
\hline Ban Po & 0.685829 & 0.937259 & 0.952583 & 0.811544 & 0.597626 \\
\hline Feng Cheng 5-Lu & 0.940048 & 0.825349 & 0.991575 & 0.882699 & 0.766084 \\
\hline Shi Tu Shu Guan & 0.859163 & 0.770689 & 0.994115 & 0.814926 & 0.656311 \\
\hline Da Ming Gong Xi & 0.804141 & 0.860691 & 0.997694 & 0.832416 & 0.689724 \\
\hline Long Shou Yuan & 0.94342 & 1 & 0.998306 & 0.97171 & 0.941023 \\
\hline An Yuan Men & 0.70878 & 1 & 0.942754 & 0.85439 & 0.648797 \\
\hline Yong Ning Men & 0.747125 & 1 & 0.958541 & 0.873563 & 0.701147 \\
\hline Nan Shao Men & 0.803022 & 1 & 0.976272 & 0.901511 & 0.774611 \\
\hline San Yao & 0.928637 & 0.788969 & 0.986819 & 0.858803 & 0.718228 \\
\hline Zhang Ba Bei Lu & 0.990325 & 1 & 0.999953 & 0.995163 & 0.990255 \\
\hline Yan Ping Men & 0.706811 & 1 & 0.941857 & 0.853406 & 0.646071 \\
\hline Tai Bai Nan Lu & 0.67251 & 1 & 0.924789 & 0.836255 & 0.598085 \\
\hline Bei Chi Tou & 0.653608 & 1 & 0.914165 & 0.826804 & 0.571287 \\
\hline Yan Xing Men & 0.624458 & 0.956748 & 0.913625 & 0.790603 & 0.521738 \\
\hline Xian Ning Lu & 0.687122 & 1 & 0.932399 & 0.843561 & 0.618638 \\
\hline Chang Le Gong Yuan & 0.636177 & 1 & 0.903555 & 0.818089 & 0.546399 \\
\hline Hu Jia Miao & 0.680187 & 1 & 0.928851 & 0.840094 & 0.608902 \\
\hline
\end{tabular}


Table 7 Coupling degree evaluation criteria

\begin{tabular}{|c|c|c|c|}
\hline $\begin{array}{l}\text { Coordination } \\
\text { degree }\end{array}$ & Coordination level & $\begin{array}{l}\text { Coordination } \\
\text { degree }\end{array}$ & $\begin{array}{l}\text { Coordination } \\
\text { level }\end{array}$ \\
\hline $0-0.09$ & $\begin{array}{l}\text { Extreme } \\
\text { imbalance }\end{array}$ & $0.50-0.59$ & Reluctant coordination \\
\hline $0.10-0.19$ & Serious disorder & $0.60-0.69$ & Primary coordination \\
\hline $0.20-0.29$ & $\begin{array}{l}\text { Moderate } \\
\text { imbalance }\end{array}$ & $0.70-0.79$ & $\begin{array}{l}\text { Intermediate } \\
\text { coordination }\end{array}$ \\
\hline $0.30-0.39$ & Mild disorder & $0.80-0.89$ & Good coordination \\
\hline $0.40-0.49$ & $\begin{array}{l}\text { On the edge } \\
\text { of imbalance }\end{array}$ & $0.90-1.00$ & Quality coordination \\
\hline
\end{tabular}

\section{Discussion of the evaluation results}

When the land intensive use system (L) is used as the input system and the rail transit operation system $(\mathrm{T})$ is used as the output system, $S_{j}(i)$ indicates the contribution of the indicator $i$ to the coordination degree of the input-output system of the $\mathrm{L}$ to $\mathrm{T}$ system. On the contrary, $S_{j}^{\prime}(i)$ indicates the contribution of the indicator $i$ to the coordination degree of the input-output system of the $\mathrm{T}$ to $\mathrm{L}$ system. The summation of the high population density station system coordination development indicator is obtained by $\sum S_{j}(i)$ and $\sum S_{j}^{\prime}(i)$ as shown in Table 9.

The effect of the coordinated development of rail transit capacity and land use can stimulate the city's potential development. It also brings the sustainable development of rail transit operation and land use to a large extent. Land use is regarded as the carrier of the coordinated development of the coordination system between city and stations. Land use provides the necessary passenger flow for the operation of the rail transit on the one hand, and the rail transit transportation capacity leads to the material form performance of the urban function change.
It can be derived from the cumulative sum $S(i)$,from the perspective of land use input indicators around the rail transit station, the sum of land use information entropy $(S(l 3)=1.414935)$ and POI information entropy $(S(l 8)=2.063163)$, which indicates that the functional mixture in the station impact area contributes the most to the coordination degree of the system of the rail transit transport capacity and land. In the coordination system around the station, the low composite degree of functions leads to an increase in long-distance travel. Secondly, the sum of floor area ratio $(S(l 1)=0.014863)$ the sum of building density $(S(l 2)=0.309041)$, the floor area ratio around the station is at a low level in the system, which indicates that it has reached an excessive level, and it is difficult to reflect the efficiency of promoting system coordination. Although there is a certain space concerning the building density around the station in comparison with the floor area ratio, the effect on the system efficiency optimization is limited. The proportion of land for public service facilities $(S(l 4)=$ 0.281879 ) exerts more impacts on the coordination degree of the system than the commercial service facilities $(S(l 5)=0.000975)$ and residential type $(S(l 6)=$ $\left.2.2 \times 10^{-14}\right)$, while the continuous investment efficiency of the public service facilities remain relatively low. The contribution of the parking lots density $(S(l 10)=0)$ is the lowest to the coordinated development. In other words, the high density of parking lots around the station is not conducive to choosing rail transit.

From the perspective of land use output indicators around the rail transit station, the percentage of the residential land $\left(S^{\prime}(l 6)=0.320878\right)$ ranks the top, while that of the total density of POI $\left(S^{\prime}(l 7)=1 \times 10^{-15}\right)$ ranks last.

1.2

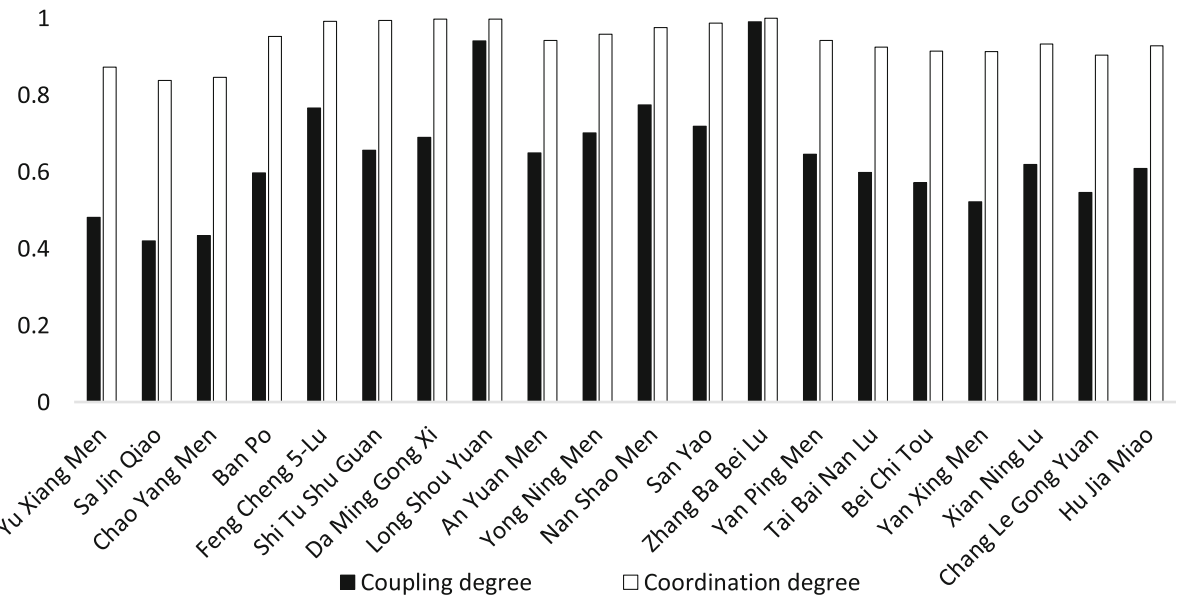

Fig. 3 Land use - rail transit capacity system coordination degree and coupling degree 
Table 8 Number of coupling types of high population density rail transit stations

\begin{tabular}{|c|c|c|c|c|c|c|}
\hline $\begin{array}{l}\text { Coupling } \\
\text { type }\end{array}$ & $\begin{array}{l}\text { On the edge } \\
\text { of imbalance } \\
(0.40,0.49]\end{array}$ & $\begin{array}{l}\text { Reluctant } \\
\text { coordination } \\
(0.50,0.59]\end{array}$ & $\begin{array}{l}\text { Primary } \\
\text { coordination } \\
(0.60,0.69]\end{array}$ & $\begin{array}{l}\text { Intermediate } \\
\text { coordination } \\
(0.70,0.79]\end{array}$ & $\begin{array}{l}\text { Good } \\
\text { coordination } \\
(0.80,0.89]\end{array}$ & $\begin{array}{l}\text { Quality } \\
\text { coordination } \\
(0.90,1.00)\end{array}$ \\
\hline low-mid & 3 & 3 & & & & \\
\hline low-high & & 1 & & & & \\
\hline mid-high & & 1 & 4 & 2 & & \\
\hline high-high & & & 2 & 2 & & 2 \\
\hline
\end{tabular}

However, From the perspective of land use as an input indicator, it is noteworthy that the proportion of land for residential $\left(S(l 6)=2.2 \times 10^{-14}\right)$ use is excessively high, and that the degree of land use function is insufficient. The degree of system coordination has the greatest influence on the proportion of residential land use and the least effects on the mixed function. In other words, controlling the proportion of residential land use, as well as improving the diversity of functions is conducive to strengthening the coordination degree of the system around the station.

With regard to rail transit operational input indicators, the sum of the average number of stations $\left(S^{\prime}(t 4)=\right.$ $0.476646)$ contributes most, while that of the daily average number of stations $\left(S^{\prime}(t 2)=1.2 \times 10^{-15}\right)$ is the lowest, which manifests that the average number of passengers on a daily basis in the station is the most conducive to the coordinated development of the land and station system. In contrast, the average daily number of rail transit interval is the least beneficial to the coordinated development. The effect of the per capita rail transit interval is higher than the average daily number of rail transit interval on the coordination of the system, indicating that the distance of the studied station type is unevenly distributed in space. In light of rail transit operational output indicators, the average daily number of passengers $(S(t 1)=1.031445)$ is the largest, and that of rail transit interval $(S(t 2)=0.018033)$ is the smallest, which reveals that the coordination degree of the system exerts the greatest impact on the total number of daily inbound and outbound stations of the station, and the least impact on the average number of stations in the station. Considering system balance, it is supposed to control the excessive concentration of passenger flow volume on the station and encourage rail transit in the course of long-distance travels.

\section{Conclusions}

Based on the mutual relationship between rail transit and land use around the rail transit station, this paper proposes the general methods and procedures for the analysis of the core factors that may influence the integrated development of the coordination system between city and stations. Taking the optimization of land use around Xi'an rail transit as an example, the research takes land use system and rail transportation capacity as input and output systems, and analyzes the coupling between stations and urban systems. By calculating the relative effectiveness of input and output, the results show that the overall coupling degree of stations with high population density and land use around in Xi'an is insufficient. On this basis, the

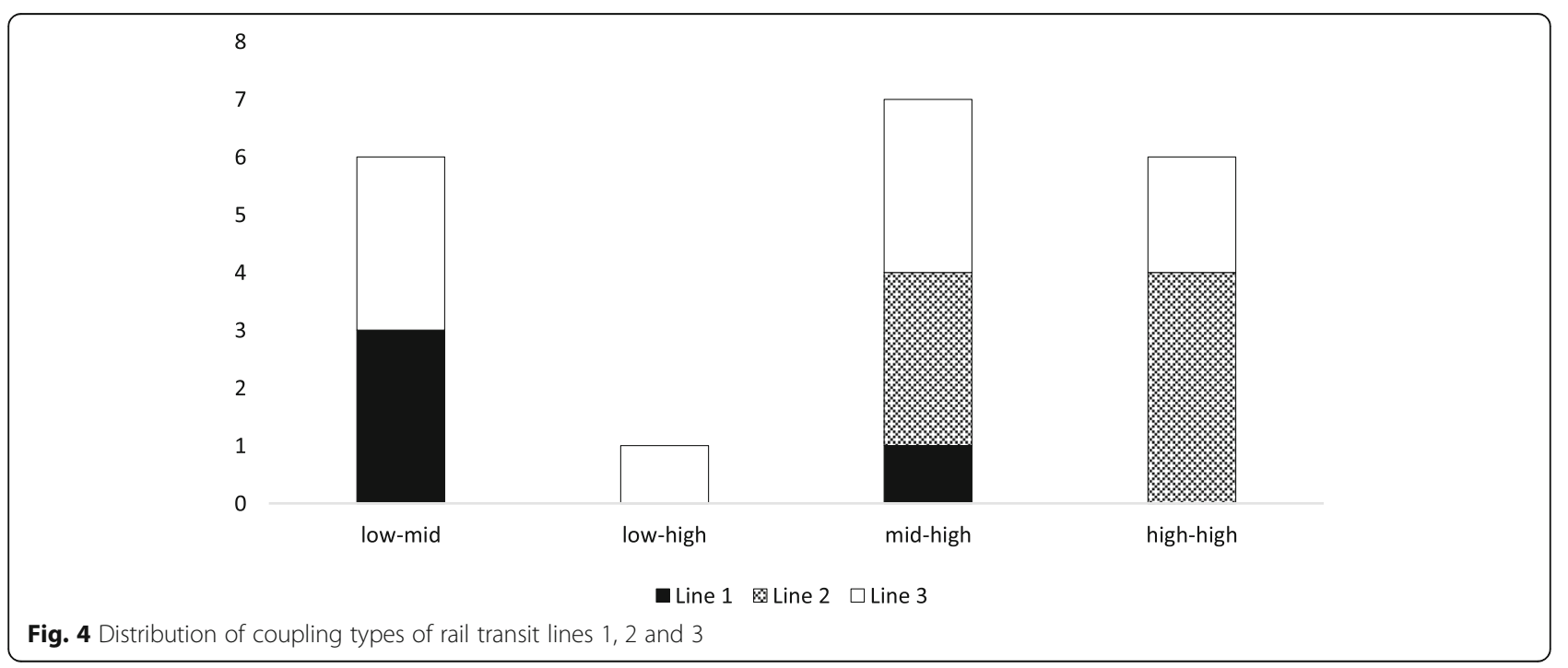


Table $9 \sum \boldsymbol{S}_{j}(\boldsymbol{i})$ and $\sum \boldsymbol{S}_{j}^{\prime}(\boldsymbol{i})$ statistics of the indicator

\begin{tabular}{lll}
\hline Indicator & $\sum \boldsymbol{S}_{j}(\boldsymbol{i})$ & $\sum \boldsymbol{S}_{j}^{\prime}(\boldsymbol{i})$ \\
\hline L1 Floor area ratio & 0.014863 & 0.021024 \\
L2 Building density & 0.309041 & $2.5 \times 10^{-15}$ \\
L3 Land use information entropy & 1.414935 & 0.280728 \\
L4 Proportion of land for public facilities & 0.281879 & 0.023358 \\
L5 Proportion of land for commercial facilities & 0.000975 & 0.00136 \\
L6 Proportion of land for resident & $2.2 \times 10^{-14}$ & 0.320878 \\
L7 Density of facilities POI & 0.066606 & $1 \times 10^{-15}$ \\
L8 Facility POI information entropy & 2.063163 & 0.026289 \\
L9 Bus line density & 0.002332 & 0.031953 \\
L10 Parking lot density & 0 & 0.088157 \\
L11 Bicycle density & 0.064983 & 0.040079 \\
T1 Average daily number of passengers & 1.031445 & 0.041003 \\
T2 Average daily number of rail transit interval & 0.018033 & $1.2 \times 10^{-15}$ \\
T3 Average daily number of trains & 0.746283 & 0.222604 \\
T4 Per capita rail transit interval & 0.030964 & 0.476646 \\
\hline
\end{tabular}

contribution of individual factors to the overall coordination degree is calculated, which provides insights into the sustainable development of rail transit and land use around the station.

Based on these topics, three strategies need to be further studied and implemented: Limiting the overemphasis on the development of land use intensity around the station, and restricting the development of motor vehicle traffic, but improving the input of land use functions, constructing a small-scale living service area with functional complex and comprehensive service capabilities, and building comfortable short-distance travel environment. Confining the continuous growth of residential proportion and enhancing the service function of residential unit Encouraging residents to make use of rail transit over long distances, which could restrain excessive traffic at individual stations.

Based on the planning and design regulations, it is likely that the research can provide reference for the formulation of indicators for improving the intensive use of land around Xi'an rail transit stations, and promote the land use to support the sustainable development of rail transit system in a more efficient way, and make land use and rail transit sustainable.

System efficiency can be achieved by separately studying subsystems of rail transit and land-use dynamic systems in the DEA model. In a combination with the relative efficiency of the subsystem, the model is able to calculate the degree of coupling that reflects the equilibrium state of the system under a particular environment. Not only is the station system complicated, but the operation and land use of the rail transit is a dynamic process. In consequence, it is still necessary to take multiple factors and a longer period into consideration in the course of studying what effects specific factors have on the system. What is more, the appropriate range of input of each factor is supposed to be further explored in a combination with the characteristics of the station itself.

\section{Abbreviations}

DEA: Data Envelopment Analysis; DMU: Decision making unit

\section{Acknowledgements}

The authors thank the editor and anonymous reviewers for their helpful comments and valuable suggestions. I would like to acknowledge all our team members.

\section{About the authors}

Quanhua Hou received the Ph.D. degrees in transportation planning and management from Chang'an University. He is a professor and deputy dean of School of Architecture, Chang'an University. He has achieved numerous scientific researches of urban and rural planning, and published more than 20 papers which indexed by SCl and El. He has led or participated in 10 research projects at the national or provincial level. In recent years, he has focused on the coordination of land use and transportation, and has rich theoretical and practical basis.

Email:houquanhua@chd.edu.cn

Yaotian Xing is currently a graduate student majoring in urban and rural planning in School of Architecture, Chang 'an University. The research direction mainly is rail transit theory and method.

Email:xingyaotian9552@163.com

Di Wang is currently a graduate student majoring in urban and rural planning in School of Architecture, Chang 'an University. The research direction mainly is rail transit theory and method.

Email:541824899@qq.com

Jiachen Liu is currently a planner in headquarters of airport construction, China West Airport Group (CWAG). The research direction mainly is rail transit theory and method. Email:1561923561@qq.com

Xiaoyang Fan is currently a graduate student majoring in urban and rural planning in School of Architecture, Chang 'an University. The research direction mainly in school is rural planning theory and method. 
Email:fxy960307@163.com

Yaqiong Duan received the Ph.D. degrees in transportation planning and management from Chang'an University. She is a teacher of School of Architecture, Chang'an University. She has published 7 papers which indexed by $\mathrm{SCl}$ and $\mathrm{El}$. She has participated in more than 10 research projects at the national or provincial level. In recent years, she has focused on the theory and method of coordination between land use and traffic.

Email:duanyaqiong@chd.edu.cn

\section{Authors' contributions}

The author takes part in the discussion of the work described in this paper All authors read and approved the final manuscript.

\section{Funding}

This research was funded by the Soft Science Research Program of Innovation Capability Support Plan Project in Shaanxi Province (No 2018KRM166), the Major Theoretical and Practical Problems of Shaanxi Social Science Projects in 2018 (No 2018Z026), the Fundamental Research Funds for the Central Universities of China (Natural Sciences) Projects (Grant No.310841172001) and the Fundamental Research Funds for the Central Universities of China (Social Sciences) Projects (Grant No.300102419631).

\section{Availability of data and materials}

The datasets used and/or analyzed during the current study are available from the corresponding author on reasonable request.

\section{Competing interests}

These no potential competing interests in our paper. And all authors have seen the manuscript and approved to submit to your journal. We confirm that the content of the manuscript has not been published or submitted for publication elsewhere.

\section{Author details}

${ }^{1}$ School of Architecture, Chang'an University, Xi'an, Shaanxi, China. ${ }^{2}$ China West Airport Group (CWAG), Xi'an, Shaanxi, China.

Received: 5 October 2019 Accepted: 8 January 2020

Published online: 21 January 2020

\section{References}

1. Jingwei B (2005) Research on urban rail transit and land control planning. Planners 02:87-90

2. Chang L, Pan H, Xiaoyu J (2011) The impact of rail transit on the planning and development strategy of peripheral areas in rail transitpolitan areas_Plann 06:60-67

3. Calthorpe P (1993) The Next American Rail transitpolis: Ecology Community, and the American Dream. Princenton Architectural Press, New York

4. Cervero R (1994) Rail transit and urban development: Land market impacts in Washington D C and Atlanta[J]. J Am Plan Assoc 60(1):83-94

5. Cervero R (2004) Transit-oriented development in the United States: experiences, challenges, and prospects. Transportation Research Board, Washington D.C

6. Papa $\mathrm{E}$, Bertolini $\mathrm{L}$ (2015) Accessibility and transit-oriented development in European rail transitpolitan areas [J]. J Transp Geogr 47:70-83

7. Zhang M (2010) Can transit-oriented development reduce peak-hour congestion? Transport Res Rec 2174:148-155

8. Zhuang X, Zhao S (2014) Effects of land and building usage on population, land price and passengers in station areas: A case study in Fukuoka, Japan. Front Archit Res 3:199-212

9. Reusser DE, Loukopoulos P, Stauffacher M et al (2008) Classifying railway stations for sustainable transitions - balancing node and place functions. Transp Geogr 16(3):0-202

10. Enrica, Filion P, MCSpurren K (2007) Smart growth and development reality: the difficult co-ordination of land use and transport objectives. Urban Stud 44(3):501-523

11. Ma Q (2009) Research progress on "TOD" in North America in recent years. Int Urban Plann s1:227-232

12. Ming $Z$, Jing $L$ (2007) Tod planning and design principles suitable for Chinese urban characteristics. J Urban Plann 01:91-96
13. Tian T, Dahua G, Deli N, Wannian F (2019) Evaluation of coordination relationship between urban land use and urban transportation__- taking the Main City of Chongqing as an example. J Southwest Univ (Natural Science Edition) 41(07):96-104

14. Ma X, Jiyu Z, Jianfeng L, Wang J, Jinhai L (2017) Study on the relationship between passenger flow characteristics and land use in Subway stations. Urban Rapid Transit Traffic 30(06):33-38

15. Choi J, Lee YJ, Kim T et al (2012) An analysis of rail transit ridership at the station-to-station level in Seoul. Transportation 39(3):705-722

16. Renne JL (2018) Transit-oriented development and ports: a national analysis in the United States. J Transp Land Use 11(1):297-304

17. Handy S (2005) Smart growth and the transportation-land use connection: what does the research tell us [J]. Int Reg Sci Rev 28(2):146-167

18. Xiangyang F, Zhongwen C (2004) Discussion on retail business form and spatial distribution along the Guangzhou Rail transit. Hum Geogr 06:11-16

19. Kong X, Yang J (2018) Passenger flow forecast of orbital stations from the perspective of land use: taking Shenzhen as an example. Geogr Sci 38(12): 2074-2083

20. Pan H, Chunyang R (2005) The spatial coupling relationship between rail transit and urban public activity center system-_taking Shanghai as an example. J Urban Plann 04:76-82

21. Ying $L$, Yin $Z$ (2016) Quantitative evaluation of street vitality and analysis of influencing factors-taking Chengdu as an example. New Archit 01:52-57

22. Hou Q, Zhang X, Li B et al (2018) Identification of low-carbon travel block based on GIS hotspot analysis using spatial distribution learning algorithm. Neural Comput \& Applic 31(9):4703-4713

23. Ma H, Yaqiong D, Quanhua H, Jizhe Z (2016) Analysis on the compilation of land use and traffic collaborative planning in hierarchical control regulations. J Northwest Univ (Natural Science) 46(05):755-758

24. Yang J, He D (2011) Study on the influence of urban block form on the energy consumption of residents. Urban Transp 9(4):21-29

25. Xuan Z, Yong L, Quanhua $\mathrm{H}$ et al (2018) Analysis of the built-up environment characteristics of low-carbon travel blocks based on gis hotspot technology. J Chang'an Univ Nat Ed 38(01):89-97

26. Quanhua $H$, Xiaoyang F, Wenqian L et al (2019) Environmental study on intensive land use mechanism of residential blocks in Xi'an under the direction of street vitality. Ekolojie 28(107):4857-4864

27. Guo Y, Li L, Guicai L et al (2015) A review of urban land use and transportation interactions at home and abroad. Int Urban Plann 30(3):33-40

28. Xie B, Chuan D (2013) Evaluation of the coordination relationship between urban rail transit and land use under Tod. Transport Syst Eng Inf 13(02):9-13-41

29. Yang $L$ (2007) Research on the basic theories and methods of the relationship between urban transportation and land use. Beijing Jiaotong University, Beijing

30. Hong Q (2013) Urban spatial intensive use under the guidance of rail transit. Southwest University, Chongqing

31. Meng H (2016) Coordination evaluation of urban transportation system and land use. Chang'an University, Xi'an

32. Wang $Z$ (2017) Research on land use evaluation around the new city rail transit station in TOD mode. Beijing University of Architecture, Beijing

33. Yuankun L, Xiafei $Y$ (2017) The relationship between the scale of urban rail transit network and population and post density. Urban Rail Transit Res 20(7):10-14

34. Kuby M, Barranda A, Upchurch C (2004) Factors influencing light-rail station boardings in the United States. Transport Res A (Policy and Practice) 38(3):0-247

35. Zhao F, Chow LF, Li MT et al (1835) Forecasting transit walk accessibility: regression model alternative to buffer method. Transport Res Rec 2003:34-41

36. Charnes A, Cooper WW, Rhodes E (1978) Measuring the efficiency of decision making units. Eur J Oper Res 2(6):429-444

37. Dong W, Weiwei L, Dong J (2013) Evaluation of coordination degree of urban rail transit and land use___ taking Shanghai as an example. J Tianjin Normal Univ (Natural Science Edition) 33(02):51-55

\section{Publisher's Note}

Springer Nature remains neutral with regard to jurisdictional claims in published maps and institutional affiliations. 